\title{
A D DEN D UM
}

TO

\section{On the Masses and Modes of Decay of Heavy Mesons Produced by Cosmic Radiation.}

\author{
(G. Stack Collaboration)
}

Nuovo Cimento, Vol. 2, 1063-1103 (1955).

The Authors of the above article regret their omission from Appendix II, pag. 1101, of the following Section:

" $3 b)$ Error. The error on $p \beta$ measured by scattering was determined from the formulae of Molière-d'Espagnat ( $\left.{ }^{1}\right)$, modified to take into account the non-normal distribution of the angles of scattering $\left({ }^{2}\right)$. The relative curves and experimental values can be found in two contributions on scattering $\left({ }^{3,4}\right)$, to the Pisa Conference 》.

(1) B. d'Espagnat: Journ. de Phys. et Rad., 13, 74 (1952).

(3) M. HuYbrechts: Thèse de Doctorat, Université Libre de Bruxelles.

(3) M. Di Corato, D. Hirschberg and B. Locatelit: Pisa Conference, June 1955, cyclostiled report, p. 275 .

(4) R. K. W. Johnston: Pisa Conference, June 1955, cyclostiled report, p. 287. 